\title{
DETERMINANTS OF INNOVATIVENESS OF THE "NEW" EUROPEAN UNION COUNTRIES BETWEEN 2004 AND 2016 - COMPARATIVE ANALYSIS
}

\author{
Irena Lacka ${ }^{1,}$ Professor \\ ${ }^{1}$ West Pomeranian University of Technology Szczecin
}

\begin{abstract}
The article discusses the problem of great multifariousness of "new" members of the European Union concerning remaining European countries and between each other. The aim of the research is a comparison within years 2004-2016 and an assessment of innovativeness of thirteen chosen countries which joined the European Union in 2004-2013. What is more, a goal is to enunciate the determinants of the assessment. The implementation of these indicators required using a comparative analysis of multiple indicator SII (Summary Innovation Index) as well as partial indicators, which describe respective areas of innovativeness in the European Union countries (according to assumptive methodology "European Innovation Scoreboard"). Against this background, conditionings of differences in innovativeness level of "new" countries of the European Union between 2004 and 2016 were conceptualized. The research indicated weak and strong sides of innovativeness which contributed achieving a determined position in innovativeness ranking. During the working on the article, the author used source literature, annual reports of the European Commission about the innovativeness of countries belonging to the European Union and INSEAD report, concerning innovativeness in common economy.
\end{abstract}

Key words: innovativeness, determinants, "new" countries of the European Union, comparative analysis JEL code: 031,033

\section{Introduction}

In modern worldwide economy, long-term development and competitiveness of a particular country extensively connect with the improvement of its innovativeness. Development trends of highly developed countries, including innovativeness leaders, rely on knowledge and innovations, human resources and cooperation in innovative processes. Experiences of those who have the highest innovation indicators show that the success is possible in those countries, which might liberate an ability to constant creation of innovations in their business entities (Larédo \& Mustar, 2001; Anderson et al., 2007; Metcalfe \& Ramlogan, 2008).

It emerges that innovativeness of farming relies on a large number of elements such as (Romer, 1994; Eicher \& Turnowsky, 1999; Lacka, 2017; The Global Innovation Index, 2017):

- human capital - well-educated people, eager to entrepreneurial and innovative activities,

- resources of financial capital - public and private expenses on research and development,

- academic and research and development infrastructure

- open research systems,

- nets of economic, social and cultural connections,

- appropriate innovative policy and useful vernacular as well as regional systems of innovativeness.

The significant number of variables, connected economic, social, cultural, stock and organizational determinants affect country's innovativeness. Their influence is visible on every level of innovativeness analyses - in global, macrocosm (in the national economy), mesocosm (regional) and microcosm (in the innovativeness of enterprises) conceptualization. Innovative activity is meant to help the agriculture to face escalating problems of the current world (detrimental demographic and social processes, challenges connected with energy requirements, climatic changes, a need of balanced growth in conditions of the alternating economic situation of farming). The higher the level of innovativeness, the better preparation of a country to functioning in "new economy" based on knowledge. It also helps them to react to changes and developmental dangers of XXI century. 
Rankings of innovativeness on a worldwide scale (The Global Innovation Index 2017, 2017) or the European Union (European Innovation Scoreboard 2017, 2017) lead that lean countries are considered to be the most innovative, having the high level of competitiveness. They are the innovation leaders and remaining states portray smaller or greater distance to them. There are four groups of countries with different levels of innovativeness in the European Union (innovation leaders, strong innovators, moderate innovators, modest innovators), but they attempt to improve their innovative position. They are supported by the European Union and innovative domestic policies.

The aim of the article is a long-term comparison and rating of innovativeness of chosen countries belonging to the European Union which joined the EU in years 2004-2013 (so-called "new" nations of the community) as well as presentation of its determinants.

\section{Material and research methodology}

To appraise the condition of innovativeness of chosen countries the author put upon figures from innovative reports of the European countries in years 2004-2016 as well as results of surveys conducted by other authors. The analysis of innovativeness level enfolds data for years 2004-2016 of following countries: Bulgaria, Croatia, Cyprus, the Czech Republic, Estonia, Lithuania, Latvia, Malta, Poland, Romania, Slovakia, Slovenia, and Hungary. Enumerated Member States belong to two groups - the majority of them are former post-communist countries which were included in the European Union after socio-economic transformation in three stages - in the year 2004, 2007, 2013. On the other hand, two of them are the capitalist countries (Cyprus and Malta) which joined the European Union in 2004. Detailed analysis of summary innovation index (SII) and its components for "new members" allow evaluating how their innovativeness has changed (likewise to the average of the European Union). It helps determining which factors impacted the level of innovativeness for chosen countries in years 2004-2016.

In case of the methodology of rating innovativeness of Member Countries of the European Union (European Innovation Scoreboard 2017. Methodology Report, 2017) experts used twenty-seven measures in four groups of indicators (innovativeness components), which take part in the determination of summary innovation index (SII), expressed as a number between 0 to 1 . Method of calculation of the SII is complex and proceeds in eight steps. The author can't discuss this process due to the limited scope of this article. It is described in the European Innovation Scoreboard 2017. Methodology Report (2017).

Partial indices are slightly modified in comparison to the methodology used in previous reports, i.e. for 2016. The components of innovativeness are classified as:

- structural factors - they create conditions to the creation of innovations; they include: human resources, attractive research systems and surrounding which fosters innovations;

- investments - this group includes expenses from public and private sectors on innovative activity, financial investments venture capital, outgoings on other than research and development innovative activity, staff training; they pertain to aspects of innovativeness such as financing and support;

- innovative activity - this category illustrates the efforts of the European entities in the area of innovativeness; for this purpose, it indicates measures such as the contribution of small and medium-sized enterprises which initiated product, process, organizational and marketing innovations. Other measures are the contribution of small and medium-sized enterprises which 
cooperated with other entities during innovative activity, the contribution of publications which are the effects of public and private cooperation, applications of inventions and appropriable patterns, protective laws to inventions (patents);

- influence - measures appearing in this group portray how innovations affect economy; they include elements such as employment in knowledge economy sector, impact on sales - the contribution of products of medium and high technology in export as well as the participation of selling products new on market and for a company.

\section{Results of surveys and discussion}

In May 2004, ten countries joined the European Union. At this moment Cyprus, Malta and the most advanced in market transmutation post-communism nations entered this formation. For more than a decade, they used the institutional and financial support of the Community to integrate into all aspects - primarily political, economic, social and cultural. This group' consisted of the Czech Republic, Estonia, Lithuania, Latvia, Poland, Slovakia, Slovenia, and Hungary. Later on, in January 2007 another two countries of former eastern coalition joined the European Union - Bulgaria and Romania. They readiness for the integration was lower because of less advanced market reforms as well as institutional transformations. The last country from the group of former communist countries that joined the EU was Croatia. This country arose after the dissolution of Yugoslavia in 90s of the XX century (similarly to Slovenia). Its integration to the European Union took place in July of 2013. Countries adopted by the European Union on following stages differentiated by:

- unusual formerly political and socio-economic systems,

- level of the advancement of market, juridical and administrative transformations,

- the number of population - the smallest country was Malta with the number of about 0,5 million people and the biggest was Poland keeping a count of 38 million residents.

Other features which differentiated "new" members were: the structure of farming and socioeconomic situation, level of GDP per one citizen (per capita), number of GDP per capita to an average for the European Union (amount expressed in PPS). Differentiation arose in the situation on the job market (unemployment rate and the highest payment rate), innovative and inventive potential, the magnitude of a technological gap to "old" members of the Community and distinct tools of economy policy (including innovative).

Thanks to the benefits of integration, countries achieved an ability to accelerate socioeconomical changes, faster economic growth and reduction of distance to more developed and wealthier members of the European Union (it pertained to Malta and Cyprus in the smallest degree because their GDP per capita was approximately similar to an average of the European Union). The degree of the depletion of disparity to prominent countries of the Community was and still is differentiated. It results from numerous reasons, among others from period of the membership, their ability to the assimilation of economy in structures of market of the European Union as well as the results of the last global crisis. In the year 2017, the essential differences in GDP, compensations, the tempo of GDP growth (much faster in the majority of "new" members) and its determinants were visible (European Economic Forecast..., 2017).

Depicted conditionings influenced the level of innovativeness of countries accepted to the European Union in years 2004-2013 to its other members. While analysing annual reports of the European Commission encompassing years 2004-2016, it is visible that formerly as well as currently, the stable differentiation of innovativeness occurs amongst the European Union 
members. Rankings of innovativeness distinct four groups of countries: leaders of innovation, sound investors (former name - innovation followers), moderate innovators and innovators achieving modest results (old name - caching-up countries). Using reports of the European Union for years 2008-2017 (i.e. Innovation Union Scoreboard 2008, 2009; European Innovation Scoreboard 2017, 2017) it is visible that the composition of particular groups overcame quite small changes. They consisted of changing of places in an almost permanent group of innovation leaders and slight variations in positions of specific members of two remaining groups - moderate and modest innovators. The thing that is decisive for affiliation to a particular group is the magnitude of SII in a given year. SII does not only describe the level of innovativeness of one specific country but also compares its magnitude to an average indicator for the European Union. In the last league table of the innovativeness of the members of the Community including data from 2016 (European Innovation Scoreboard 2017, 2017) following countries were distributed among particular groups (along with SII magnitudes):

- innovation leaders - Sweden (0.708), Denmark (0.675), Finland (0.646), the Netherlands (0.639), Great Britain (0.618), Germany (0.609); had the highest indicators of innovativeness ( $20 \%-40 \%$ above the average of the whole community which added up to 0.503 );

- strong innovators - Austria (0.599), Luxemburg (0.599), Belgium (0.597), Ireland (0.571), France (0.539), Slovenia (0.482); their SII assumed values from $90 \%$ to $120 \%$ of the average for the European Union;

- moderate innovators - the Czech Republic (0.416), Portugal (0.409), Estonia (0.393), Lithuania (0.391), Spain (0.386), Malta (0.378), Italy (0.371), Cyprus (0.369), Slovakia (0.345), Greece (0.337), Hungary (0.332), Latvia (0.287), Poland (0.270), Croatia $(0.270)$; members of this group achieved indicators of innovativeness between $50 \%$ and $90 \%$ of the average SII for the Community;

- modest innovators - Bulgaria $(0,234)$, Romania $(0.167)$; these countries achieved indicators of innovativeness lower than 50 \% of the average for the European Union.

This European Commission's report dedicated for innovativeness of the European Union countries leads to long-term tendencies about the magnitude of summary innovation index SII in years 2010-2016. It shows that in the case of fifteen countries SII grew at that time, but it depleted in thirteen countries. The tempo of innovative growth was uneven. In some countries, the indicator grew at last $8 \%$ (Lithuania $21 \%$, Malta $12.2 \%$, Great Britain $11.7 \%$, the Netherlands $10.4 \%$, Austria $8.9 \%$, Latvia $8.5 \%$ and Slovakia $8.0 \%$ ). On the other hand, remaining countries, in which innovativeness improved, set down lower than $5 \%$ SII growth. These countries are: Ireland $3.5 \%$, France $2.8 \%$, Sweden $2.3 \%$, Poland $2 \%$, Belgium $1.4 \%$, Luxemburg $1.4 \%$, Greece $0.7 \%$, Bulgaria $0.1 \%$.

In thirteen countries of the European Union in years 2010-2016 a decline of the indicator occurred, however, on distinct level. Among them, there were following countries with mentioned quantity of SII decline: Slovenia $(-0.2 \%)$, Italy $(-0.2 \%)$, Croatia $(-1.4 \%)$, Spain $(-1.8 \%)$, Portugal $(-2.4 \%)$, Denmark $(-2.8 \%)$, Hungary $(-3.5 \%)$, the Czech Republic $(-3.5 \%)$, Estonia ($3.6 \%)$, Germany $(-3.7 \%)$, Finland $(-5,1 \%)$, Cyprus $(-12.7 \%)$ and Romania $(-14.1 \%)$.

The analysis of the European Commission's reports concerning innovativeness of the European Union countries in the even more prolonged period (years 2004-2016) shows that the first stage, it means years 2004-2009 growth of the summary innovation index occurred. The only exception was 
the decline of SII indicator of Lithuania in years 2006-2010 of $0.7 \%$ from 0.244 to 0.227 (Innovation Union Scoreboard 2010, 2011; Innovation Union Scoreboard 2012, 2013).

In years 2004-2010, the biggest tempo of innovation index was achieved by "new" member nations. Following factors influenced this process:

- upgrading the economy to more competitive because of the necessity to prepare entities of those countries to fulfil requirements of the European Union markets,

- a change of innovative policy and usage of efficient tools oriented towards the growth of creative activity among entities as well as public scientific institutions,

- accessibility of differentiated, clear and balanced system of encouragements to innovations, mixed system of financing innovation (subventions, tax credits, repayable instruments of financing innovations, development of finances venture capital),

- redevelopment of domestic and regional systems of innovativeness,

- changes in financing and organizing higher education and research and development sector,

- usage of the EU subsidies for supporting innovative processes, upgrading value of human capital, transfer and commercialization of knowledge and technology, research and development projects, creation of relations between education and industry,

- growth of financing innovative activities (including research and development) from the public and private finances as well as a slow change in financing structure (the increase of private sector's participation in financing research and development and other forms of innovative activity).

Portrayed reforms and innovative activities fulfilled "new" member nations in different tempo and areas. It resulted from differentiated economy structures, different socio-economic potentials, and innovative countries as well as their level of assimilation with the community (including their membership to Eurozone). In all discussed countries they led to the improvement of innovativeness indicators in years 2004-2009.

However, in later stage under the influence of economy crisis as well as other factors (growth of economic policy's insecurity, new economic and political priorities after the change of the government, problems of the Eurozone) occurred smaller pace of the innovative growth in new countries of the European Union. In some of them, in years 2010-2016 lowering of SII happened (Community Innovation Survey 2014, 2014). The subject of analysis of the article is the rating of innovativeness in "new" members of the European Union, so in Tables 1 and 2 there are data about SII magnitude in surveyed period. Concerning differences in used methodologies of the European Commissions' reports and discrepancy in data presented in following reports about innovativeness, the author acknowledged that the whole surveying period will split into two periods 2004-2009 and 2010-2014.

Data included in Tables 1 and 2 show that new members of the European Union in the surveyed period had quite differentiated levels of innovativeness. In majority, there were countries with SII diverging in smaller or greater level from the European average (which is confirmed by the last report of the European Commission in 2017).

In years 2004-2009, only Slovenia and Estonia (which belonged to the group of chasing lands, currently called strong innovators) achieved SII above the European Union's average. Remaining new members of the community belonged to two groups - moderate and modest innovators. SII magnitudes from the Table 1 show that these countries in years 2004-2009 (after joining the European Union and before the global economic crisis) exhibited the reduction of technological 
distance to the European Union's average. The improvement of innovativeness was fastest in Slovenia, the Czech Republic, Estonia, Malta, Cyprus, Lithuania, and Hungary. In the period of economic situation's crisis, some of them worsened their innovativeness indicators.

SII of the EU and its "new" countries (2004-2009)

Table 1

\begin{tabular}{|l|l|l|l|l|l|l|}
\hline S1 & $\mathbf{2 0 0 4}$ & $\mathbf{2 0 0 5}$ & $\mathbf{2 0 0 6}$ & $\mathbf{2 0 0 7}$ & $\mathbf{2 0 0 8}$ & $\mathbf{2 0 0 9}$ \\
\hline UE27 & 0.429 & 0.431 & 0.447 & 0.466 & 0.475 & 0.478 \\
\hline BG & 0.172 & 0.174 & 0.178 & 0.206 & 0.221 & 0.231 \\
\hline CZ & 0.344 & 0.346 & 0.368 & 0.392 & 0.404 & 0.415 \\
\hline CY & 0.370 & 0.363 & 0.381 & 0.433 & 0.471 & 0.479 \\
\hline EE & 0.413 & 0.409 & 0.421 & 0.443 & 0.454 & 0.481 \\
\hline HU & 0.266 & 0.273 & 0.287 & 0.305 & 0.316 & 0.328 \\
\hline LV & 0.194 & 0.204 & 0.215 & 0.239 & 0.239 & 0.261 \\
\hline LT & 0.264 & 0.273 & 0.287 & 0.294 & 0.294 & 0.313 \\
\hline MT & 0274 & 0.280 & 0.292 & 0.215 & 0.329 & 0.343 \\
\hline PL & 0.264 & 0.272 & 0.282 & 0.293 & 0.305 & 0.317 \\
\hline RO & 0.209 & 0.205 & 0.223 & 0.249 & 0.277 & 0.294 \\
\hline SK & 0.257 & 0.273 & 0.298 & 0.299 & 0.314 & 0.331 \\
\hline SI & 0.388 & 0.393 & 0.412 & 0.429 & 0.446 & 0.466 \\
\hline
\end{tabular}

S1 - the European Union or countries symbol

Author's elaboration based on: Innovation Union Scoreboard 2008, European Communities, Luxembourg, 2009, http://aei.pitt.edu/46017/1/innovation_scoreboard_2008_2.pdf. Access 12.01.2018; European Innovation Scoreboard 2009, European Commission, http:// http://aei.pitt.edu/46018/1/innovation_scoreboard_2009.pdf. Access 12.01.2018.

SII of the EU and its "new" countries (2010-2016)

\begin{tabular}{|l|l|l|l|l|l|l|l|}
\hline \multicolumn{1}{|c|}{ S1 } & $\mathbf{2 0 1 0}$ & $\mathbf{2 0 1 1}$ & $\mathbf{2 0 1 2}$ & $\mathbf{2 0 1 3}$ & $\mathbf{2 0 1 4}$ & $\mathbf{2 0 1 5}$ & $\mathbf{2 0 1 6}$ \\
\hline UE 28 & 0,493 & 0.496 & 0.489 & 0.495 & 0.489 & 0.497 & 0.503 \\
\hline BG & 0.234 & 0.245 & 0.199 & 0.223 & 0.223 & 0.227 & 0.234 \\
\hline CZ & 0.434 & 0.439 & 0.423 & 0.421 & 0.412 & 0.421 & 0.416 \\
\hline CY & 0.432 & 0.448 & 0.426 & 0.437 & 0.367 & 0.368 & 0.369 \\
\hline EE & 0.411 & 0.439 & 0.446 & 0.451 & 0.427 & 0.450 & 0.393 \\
\hline HR & 0.277 & 0.276 & 0.254 & 0.265 & 0.243 & 0.267 & 0.270 \\
\hline HU & 0.350 & 0.349 & 0.325 & 0.326 & 0.329 & 0.332 & 0.332 \\
\hline LV & 0.244 & 0.257 & 0.235 & 0.241 & 0.270 & 0.302 & 0.287 \\
\hline LT & 0.288 & 0.286 & 0.302 & 0.304 & 0.299 & 0.323 & 0.391 \\
\hline MT & 0.318 & 0.311 & 0.307 & 0.359 & 0.397 & 0.403 & 0.378 \\
\hline PL & 0.261 & 0.263 & 0.251 & 0.254 & 0.251 & 0.257 & 0.270 \\
\hline RO & 0.236 & 0.242 & 0.217 & 0.205 & 0.168 & 0.157 & 0.167 \\
\hline SK & 0.306 & 0.329 & 0.340 & 0.357 & 0.328 & 0.348 & 0.345 \\
\hline SI & 0.483 & 0.490 & 0.483 & 0.480 & 0.487 & 0.483 & 0.482 \\
\hline
\end{tabular}

S1 - the European Union or countries symbol

Author's elaboration based on: European Innovation Scoreboard 2017, European Commission, 2017, http://ec.europa.eu/growth/industry/innovation/facts-figures/scoreboards_en. Access 12.01.2018.

In years 2004-2016, the weakest results and the smallest progress in ablating technological gap to highly developed countries, and even to remaining new members of the Community showed: Romania, Bulgaria, Latvia, and Poland. Croatia, which has low SII cannot be rated in the same way as countries which joined the EU between 2004 and 2007 because of the relatively shortest period of assimilation.

In years 2008-2010, the deterioration of the economic situation in the aftermath of the global crisis primarily affected countries such as Cyprus, Slovenia, the Baltic states (Latvia, Estonia, and 
Lithuania) as well as Romania. Afterwards, in the second wave of the crisis in the year 2012 bad economic situation affected Bulgaria and Latvia. In Poland, even the tempo of the economic growth lowered, the disaster occurred on the relatively high level to remaining EU countries. Despite that, under the influence of the dilution of the economic growth and deterioration of entrepreneur's optimism and their lower innovative activity in years 2010-2016, significant diminution of SII happened.

Partial indicators decide about the magnitude of the summary innovation index. They also help understanding why some countries are more innovative than others. They enable finding strong and weak sides of innovativeness of particular nations. It leads specific determinants of innovativeness.

To recognize them, in the case of new members of the Community, Table 3 includes partial indicators of innovativeness which describe particular innovative components in the year 2016.

Component indices of innovation groups of new EU Member States in 2016

Table 3

\begin{tabular}{|c|c|c|c|c|c|c|c|c|c|c|}
\hline $\mathbf{S}^{1}$ & $\begin{array}{c}\text { Human } \\
\text { resources }\end{array}$ & $\begin{array}{c}\text { Research } \\
\text { System }\end{array}$ & $\begin{array}{c}\text { Innova- } \\
\text { tion } \\
\text { friendly } \\
\text { environ- } \\
\text { ment }\end{array}$ & $\begin{array}{c}\text { Finance } \\
\text { and } \\
\text { support }\end{array}$ & $\begin{array}{c}\text { Firm } \\
\text { invest- } \\
\text { ments }\end{array}$ & $\begin{array}{c}\text { Innova- } \\
\text { tors }\end{array}$ & $\begin{array}{c}\text { Linka- } \\
\text { ges }\end{array}$ & $\begin{array}{c}\text { Intellec- } \\
\text { tual } \\
\text { assets }\end{array}$ & $\begin{array}{c}\text { Employ- } \\
\text { ment } \\
\text { impacts }\end{array}$ & $\begin{array}{c}\text { Sales } \\
\text { impact }\end{array}$ \\
\hline UE28 & 0.481 & 0.451 & 0.497 & 0.473 & 0.475 & 0.478 & 0.479 & 0.493 & 0.538 & 0.664 \\
\hline BG & 0.286 & 0.116 & 0.289 & 0.091 & 0.247 & 0.064 & 0.089 & 0.487 & 0.526 & 0.216 \\
\hline CZ & 0.387 & 0.334 & 0.410 & 0.438 & 0.479 & 0.411 & 0.316 & 0.299 & 0.513 & 0.613 \\
\hline CY & 0.442 & 0.469 & 0.229 & 0.264 & 0.204 & 0.483 & 0.220 & 0.546 & 0.322 & 0.410 \\
\hline EE & 0.486 & 0.378 & 0.491 & 0.703 & 0.319 & 0.131 & 0.290 & 0.476 & 0.376 & 0.416 \\
\hline HR & 0.308 & 0.162 & 0.209 & 0.288 & 0.449 & 0.344 & 0.255 & 0.195 & 0.333 & 0.161 \\
\hline HU & 0.258 & 0.224 & 0.406 & 0.251 & 0.371 & 0.080 & 0.303 & 0.230 & 0.681 & 0.632 \\
\hline LV & 0.371 & 0.152 & 0.696 & 0.429 & 0.184 & 0.067 & 0.208 & 0.245 & 0.454 & 0.301 \\
\hline LT & 0.493 & 0.140 & 0.604 & 0.549 & 0.419 & 0.443 & 0.545 & 0.260 & 0.358 & 0.217 \\
\hline MT & 0.252 & 0.354 & 0.480 & 0.130 & 0.283 & 0.377 & 0.094 & 0.796 & 0.841 & 0.309 \\
\hline PL & 0.308 & 0.133 & 0.364 & 0.289 & 0.356 & 0.012 & 0.134 & 0.383 & 0.473 & 0.356 \\
\hline RO & 0.198 & 0.121 & 0.390 & 0.102 & 0.050 & 0.000 & 0.148 & 0.122 & 0.199 & 0.401 \\
\hline SK & 0.384 & 0.212 & 0.306 & 0.409 & 0.290 & 0.159 & 0.313 & 0.190 & 0.601 & 0.681 \\
\hline SI & 0.688 & 0.410 & 0.497 & 0.228 & 0.589 & 0.427 & 0.531 & 0.460 & 0.399 & 0.489 \\
\hline SOU
\end{tabular}

Source: author's developed table based on: Innovation Union Scoreboard 2017, European Commission, 2017, http://ec.europa.eu/growth/industry/innovation/facts-figures/scoreboards_pl (access: 10.01.2018).

While analysing indicators of particular components, it can be noticed that countries belonging to the group of modest innovators (Romania and Bulgaria) and those which are on the concluding positions in the group of moderate innovators (Croatia, Poland, Latvia) have weak sides of innovativeness such as poorly opened and imperfect research systems, which exhibit rare contacts with international environment and sparsely connections with the entrepreneurial sector. It impacts the discrepancy between the supply of the research and development approach and the demand from entities. It also affects the insufficient transfer of knowledge and technology as well as diminutive commercialization of new solutions.

Low innovativeness of these countries is determined by following factors: minuscule participation of innovative small and medium-sized enterprises, diminutive engagements of subjects from this sector into financing research and development and other displays of creative activities. In these countries, the structure of financing innovation does not conform with OECD countries, and the system of supporting innovative movement relies mainly on public financials 
(domestic and European). Functional finances venture capital and potent stimulants such as tax credits and reversing instruments did not develop. Entrepreneurs' attitudes and innovative activities develop too slowly - only a few owners of small and medium-sized enterprises consider innovations as factors of improving competitiveness. Entrepreneurs unwillingly cooperate in creative processes with other companies and research institutions (Radas \& Božić, 2009). They rarely function in an industrial cluster's structure. All of above factors have small impact on innovative entities as well as the small number of products, process, marketing and organizational innovations. Besides, they cause brittle results in the area of the influence of changes on sales what is portrayed by low partial indicators describing participation of incomes from the disposals of new products (for market or company) in overall profits of an entity and revenues from selling average and high technology products in the income of export. Inefficient innovative economy describes how indicators of innovation impact employment - there is a small number of workplaces in knowledge-intensive sectors (despite quite good signs in the area of human resources). It has a negative impact on the appearing of innovations as effects of using knowledge and technology into the development and improvement of economy's competitiveness.

\section{Conclusions, proposals, recommendation}

The surveys on the innovativeness of "new" countries belonging to the European Union and its determinants lead to conclusion that their innovativeness is diversified, what is caused by factors such as:

- membership to a particular political and socio-economical system before the affiliation,

- the magnitude of a country and the date of joining the European Union. To a greater extent,

- economy structure might have an impact as well as its potency of relations with markets in the formation,

- the level of advancement of reforms in the new members in many important for economy's innovativeness sectors - research systems, financing innovations, innovativeness attitudes among entrepreneurs, the change of the perception of innovation

- recognition by all entities (government, entrepreneurs, scientists, purchasers), that innovation is an important factor of competitiveness on a micro, meso and macroscale.

The analysis of partial innovativeness indicators for each country which joined the European Union in years 2004-2013 shows that:

- some of the countries which achieved the most prolonged period of membership did not manage to remove the significant technological gap to some highly developed European countries (Romania, Bulgaria, Poland and Latvia),

- these countries also have a worse position to nations from former eastern coalition which intensively use strong sides of innovativeness (Slovenia, the Czech Republic, Estonia, Lithuania, Hungary),

- in countries with low rates of innovativeness should be strengthened these aspects of innovativeness which are currently their weak sides,

- their innovation policy needs improvement - it is not very effective; currently, it is too slowly increasing the activity of entrepreneurs and scientists in innovative processes; it also does not advance the development of new forms of financing innovations. 


\section{Bibliography \\ Books}

1. Larédo, P., Mustar, P. (2001). Research and Innovation Policies in the new global economy. An international comparative analysis. Cheltenham: EE Publishing.

\section{Articles}

2. Anderson, T.R., Daim, T.U., Lovoie, F.F. (2007). Measuring the efficiency of university technology transfer. Technovation, 27, p. 306-318.

3. Baruk, J. (2016). Innowacyjnosc przedsiebiorstw w panstwach Unii Europejskiej [Innovativeness of the enterprises in European Union States], Wiadomości Statystyczne, 8, p. 64-78.

4. Eicher, T.S., Turnowsky, S.J. (1999). Non-scale models of economic growth. Economic Journal, 109, p. 394415.

5. Lacka, I. (2017). Barriers to the development of Polish SME in the light of the research results of innovativeness of the economy and companies. Proceedings of the 2017 International Conference "Economic Science for Rural Development", 44, p.99-109.

6. Radas, S., Božić L. (2009). The antecedents of SME innovativeness in an emerging transition economy, Technovation, 29, p. 438-450.

7. Metcalfe, S., Ramlogan, R. (2008). Innovation system and the competitive process in developing economies. The Quarterly Review of Economics and Finance, 48, 433-466.

8. Romer, S.M. (1994). The origins of endogenous growth. The Journal of Economic Perspectives, 8, p. 3-22.

\section{Internet sources}

9. Community Innovation Survey 2014. (2014), http://ec.europa.eu/eurostat/cache/metadata/en/inn_cis9_esms.htm. Access: 9.01.2018.

10. European Economic Forecast - Autumn 2017. (2017), https://ec.europa.eu/info/sites/info/files/economyfinance/autumn_2017_economic_forecast_-_statistical_annex.pdf. Access: 10.01.2018.

11. European Innovation Scoreboard 2009. (2010), European Commission, http:// http://aei.pitt.edu/46018/1/innovation_scoreboard_2009.pdf. Access 12.01.2018.

12. European Innovation Scoreboard 2017. (2017). Brussels: European Commission. Retrieved: http://europa.eu/growth/industry/innovation/facts-figures/scoreboards_pl. Access: 10.01.2018.

13. Innovation Union Scoreboard 2008. (2009). Luxembourg, European Communities, http://aei.pitt.edu/46017/1/innovation_scoreboard_2008_2.pdf. Access 12.01.2018;

14. Innovation Union Scoreboard 2010. (2011). Inno Metrics, https://ec.europa.eu/research/innovationunion/pdf/iu-scoreboard-2010_en.pdf. Access 12.01.2018

15. The Global Innovation Index 2017: Innovation Feeding the World. (2017). Ithaca, Fontainebleau, and Geneva: Cornel University, INSEAD, and WIPO, http://www.wipo.int/edocs/pubdocs/en/wipo_pub_gii_2017.pdf. Access 12.01.2018. 